\title{
O PENSAMENTO ESTRATÉGICO EM SUN TZU, MAQUIAVEL, CLAUSEWITZ E CARLOS MATUS
}

\author{
Romeu Porto Daros ${ }^{1}$
}

\begin{abstract}
Resumo: O presente artigo tem o objetivo de fazer um passeio panorâmico pelo pensamento estratégico de quatro expoentes deste campo na história da humanidade: dois generais e teóricos da estratégia militar (Sun Tzu e Carl Von Clausewitz) e dois políticos e teóricos da estratégia governamental (Nicolau Maquiavel e Carlos Matus). A produção intelectual deles foi fundamental para a elaboração dos conceitos contemporâneos de estratégia e tática que são largamente utilizados no planejamento estratégico de governos e, também, no âmbito da iniciativa privada.
\end{abstract}

Palavras-chave: Estratégia. Tática. Planejamento Estratégico. Política. Guerra.

\section{INTRODUÇÃO}

O termo estratégia (strategos) tem suas origens na Grécia Antiga, nasceu associado à arte da guerra e relacionava-se com as atribuições do comandantechefe da organização militar. Assim, passou a significar a arte do general, destacando as habilidades psicológicas e comportamentais do comandante militar no exercício da sua função. Ainda na Antiguidade, ao tempo de Péricles (495-429 a.C.), passou a ser associada as habilidades gerenciais, como, administração, liderança e poder (MINTZBERG; QUIN, 2001). Com Alexandre Magno (356-323 a. C.) a palavra se associou à habilidade de empregar o uso da força para sobrepujar o adversário e estabelecer um sistema unificado de governança global. Principiou-se, então, o uso do termo estratégia associado, também, ao planejamento de governo. Com o advento da II Revolução Industrial no final do século XIX e, principalmente no inicio do século XX, o termo começou a ter aplicação ao mundo dos negócios (OLIVEIRA, 2009).

$\mathrm{Na}$ atualidade o conceito de estratégia passou a ser largamente associado ao de planejamento para designar um conjunto de metodologias, processamentos e técnicas conhecidos como planejamento estratégico. Assim, o planejamento da

1 Doutor em Literatura e mestre em Estudos da Tradução. Universidade Federal de Santa Catarina/UFSC. Email: romeud@hotmail.com 
guerra, realizado pelo chefe do exército com a ajuda de seus generais, fundou a sua versão governamental, envolvendo o governante e seus assessores, e, também, o planejamento empresarial, envolvendo o diretor-chefe e seus gerentes. Em algumas experiências o planejamento estratégico teve seu alcance ampliado envolvendo, no caso das coorporações privadas, um grande número de funcionários e, no âmbito da esfera pública, amplas parcelas da sociedade organizada e da população no planejamento das cidades.

No percurso histórico pelo qual trilhou a evolução do conceito de estratégia há que se destacar a contribuição de quatro grandes pensadores que foram, também, cada um ao seu modo, homens de ação que na prática do seu cotidiano testaram e reelaboraram as premissas do planejamento estratégico. São eles: Sun Tzu, Nicolau Maquiavel, Carl Von Clausewitz e Carlos Matus.

De tal modo, o artigo que ora se desenvolve tem o objetivo de fazer um passeio panorâmico pelo pensamento estratégico destes quatro expoentes deste campo na história da humanidade: dois generais e teóricos da estratégia militar (Sun Tzu e Clausewitz) e dois políticos e teóricos da estratégia governamental (Maquiavel e Carlos Matus). A produção intelectual deles foi fundamental para a elaboração dos conceitos contemporâneos de estratégia e tática que são largamente utilizados no planejamento estratégico de governos e, também, no âmbito da iniciativa privada.

\section{O PENSAMENTO ESTRATÉGICO EM SUN TZU}

Pouco se sabe documentalmente sobre a vida de Sun Tzu, o general chinês e teórico de estratégia militar. Segundo o historiador chinês Ssu-ma Chi'ien, em um escrito que data cerca de 100 a.C., ele era "[...] súdito do rei de Wu, foi o homem mais versado que jamais existiu na arte militar” (SUN TZU, 2006, p. 7). Ele era natural do estado de Chi, e seu texto remonta à turbulenta época dos Estados Guerreiros da China. Diz-se que pertencia a aristocracia militar e teve como mestre o próprio avô. Sua obra manteve-se viva por mais de dois mil anos e chegou ao mundo ocidental por meio de um missionário jesuíta em Pequim, o padre Jean Joseph Marie Amiot, cuja tradução de A Arte da Guerra foi publicada em Paris, em 1772.

O livro é um tratado sobre planejamento, estratégia e liderança e suas ideias foram adotadas por estrategistas da esfera pública e privada. Samuel B. Griffith, tradutor do chinês para o inglês de A Arte da Guerra, diz no prefácio da edição de 1996 que a obra 
[...] não merece nossa atenção e interesse meramente como uma curiosidade do mundo antigo. A arte da guerra é bem mais que isso. Trata-se de uma obra abrangente e bem-elaborado, que se destaca pelo caráter perceptivo e imaginativo que durante séculos lhe garantiu posição de destaque no cânone da literatura militar chinesa. (SUN TZU, 1996, p. 7)

A ideia central de seu pensamento estratégico assenta-se na lógica de que uma estratégia vitoriosa é aquela que consegue evitar o uso das armas, ou seja, a suprema arte da guerra é a não guerra, é o uso de uma estratégia que permita alcançar a vitória sem a necessidade do confronto armado. Sun Tzu sustenta que "[...] obter cem vitórias em cem batalhas não representa o máximo da habilidade. O máximo da habilidade é subjugar o inimigo sem lutar" (1996, p. 33).

Para ele o conhecimento é um recurso valioso e é através dele que o estrategista consegue fazer o cálculo necessário para a vitória na guerra:

Conhece teu inimigo e conhece-te a ti mesmo; se tiveres cem combates a travar, cem vezes serás vitorioso.

Se ignoras teu inimigo e conheces a ti mesmo, tuas chances de perder e de ganhar serão idênticas.

Se ignoras ao mesmo tempo teu inimigo e a ti mesmo, só contarás teus combates por tuas derrotas. (2006, p. 23)

Neste pequeno trecho de sua obra, Sun Tzu alcança instituir as bases fundamentais para a elaboração dos conceitos de tática e estratégia e, ainda, embute uma metodologia de processamento que serviu de referência para modernas técnicas de análise estratégica, dentre as quais a conhecida matriz $\mathrm{SWOT}^{2}$, que utiliza os conceitos de força, fraqueza, ameaças e oportunidades como elementos constitucionais de análise estratégica para o estudo de cenários e do ambiente interno e externo das organizações.

Outros trechos essenciais do pensamento estratégico de Sun Tzu que constam de sua obra A Arte da Guerra (2006) são:

Quão lamentável é arriscar tudo em um único combate, negligenciando a estratégia vitoriosa, e fazer com que o destino de tuas armas dependa de uma

2 A sigla SWOT é a abreviatura das palavras inglesas strengths, weaknesses, opportunities e threats que significam respectivamente: forças, fraquezas, oportunidades e ameaças. No Brasil é comum o uso da sigla FOFA. 
única batalha! (p. 15)

O objetivo de um general hábil é apoderar-se do reino inimigo quando este está intato; assim suas tropas não se esgotarão e seu triunfo será completo. Esta é a arte da estratégia vitoriosa. (p. 21)

Um exército vitorioso ganha antes de ter deflagrado a batalha; um exército fadado à derrota combate na esperança de ganhar. (p. 26)

A invencibilidade está na defesa; a possibilidade de vitória, no ataque. (p. 24)

Jamais repitas uma tática vitoriosa, mas responde às circunstâncias segundo uma variedade infinita de métodos. (p. 34)

Da mesma forma que a água que corre evita as alturas e se precipita nas planícies, assim um exército evita a força e ataca a fraqueza. (p. 35)

O general hábil tirará partido de todas as circunstâncias, inclusive as mais perigosas e as mais críticas. Sabe manipular não somente o exército que comanda, mas também o dos inimigos. As tropas, quaisquer que sejam, não têm qualidades constantes que as tornem invencíveis. (p. 35)

Segue esse princípio. Não deixes escapar nenhuma oportunidade. (p. 36)

Prevê tudo, dispõe de tudo. E cai sobre o inimigo quando ele crê que estás muito distante: nesse caso, anuncio-te a vitória. (p. 38)

Se um general ignora o ponto fraco e o forte do inimigo que deve combater, se não conhece a fundo o terreno que ele ocupa no momento, nem os que pode ocupar em função das circunstâncias, talvez contraponha ao que há de melhor no exército inimigo o que há de pior no seu. (p. 58)

Conhece-te a ti mesmo, conhece teu inimigo. Tua vitória jamais correrá risco. Conhece o lugar, conhece o tempo. Então, tua vitória será total. (p. 60)

A guerra deve ser a última solução. Os combates, quaisquer que sejam os resultados, têm sempre um gosto amargo mesmo para os próprios vencedores. Só 
se deve travá-Ios quando não houver outra saída. [...] um general deve evitar o combate. [...] Nunca esqueças que teu objetivo, ao desencadear a guerra, deve ser o de conseguir para o Estado a glória, o esplendor e a paz, e não o de semear o tumulto, a desolação e a morte. (p. 73)

Como se observa, Sun Tzu, ao discorrer sobre a arte da guerra faz-nos visualizar como seria na prática o uso de conceitos, tais como: circunstâncias; oportunidades; ameaças; análise de forças e fraquezas; tempo e espaço; eficiência e eficácia, dissuasão, tática etc. Enfim, conceitos fundamentais do moderno planejamento estratégico. É importante não perder de vista o que para ele é o elemento central de uma estratégia vitoriosa, ou seja, o supremo planejamento é aquele que logra evitar o uso das armas, que alcança o objetivo sem a necessidade do combate, sem a necessidade de destruição de recursos que possam ser úteis para a etapa posterior do projeto de uma organização, seja ela pública ou privada.

\section{O PENSAMENTO ESTRATÉGICO EM NICCOLÒ MACHIAVELLI}

Conhecido no Brasil pelo nome aportuguesado de Maquiavel, ele nasceu em Florença, na Itália. Foi um teórico de estratégia governamental e militar e, ao mesmo tempo, um homem de múltiplas habilidades, uma vez que exerceu as atividades de filósofo, historiador, dramaturgo, diplomata, dentre outras. Intelectual renascentista é considerado o fundador das ciências políticas moderna. A eficácia do seu texto, o que lhe garantiu repercussão e longevidade, fundamentava-se na premissa de que era necessário descrever a política, o Estado e seu governo como realmente são e não de maneira idealizada. Compôs a maior parte das suas obras no exílio, a partir de1512, das quais a mais célebre é o tratado $O$ Príncipe, concluído em 1515, mas publicado apenas postumamente, em 1532. Neste encontram-se as bases do seu pensamento político.

Entre os anos de 1517 e 1520, escreveu A Arte da Guerra. A obra é um tratado escrito na forma de diálogo, gênero comum no período, e é composto por sete livros. Florença era naquele tempo uma das mais importantes cidades da Europa e cujos interesses financeiros e comerciais se estendiam por todo o continente, no entanto, a Itália encontrava-se dividida em cidades-estado e era constantemente invadida por potências estrangeiras. De tal modo, ela necessitava de líderes militares e políticos que lograssem unificar o norte do 
país e expulsar as forças forasteiras do seu território. Com esse objetivo, Maquiavel elaborou esta obra na qual instituiu conceitos novos como a organização do exército, a hierarquia de comando, a formação de soldados, o estado-maior e os códigos de leis militares. Segundo ele a intenção do livro “[...] não foi precisamente mostrar-vos como eram organizados os exércitos antigos, mas como nesses tempos se poderia organizar um exército com mais virtù do que se tem hoje (1971, p. 180) ${ }^{3}$. Virtù é um conceito introduzido por Maquiavel para retratar a importância dos soldados serem recrutrados entre homens de princípios nacionalistas para não se deixar o exército a mercê de mercenários ${ }^{4}$. Sobre estes diz: “[...] não há infantaria mais perigosa do que a composta de mercenários - o príncipe será obrigado a fazer continuamente a guerra, mantendo-os a soldo, ou correrá o risco de que o apeiem do trono (2007, p. 111).

Para o florentino, espelhando-se no exemplo da cultura romana da antiguidade, a guerra deve ser um assunto de Estado e dela deve ocupar-se diretamente o governante. Desse modo, a guerra no seu tempo era um assunto vital para a autonomia e sobrevivência do país. Criticando a situação dos Estados italianos ${ }^{5}$ assenta que:

Todo Estado bem ordenado deseja que a arte da guerra seja, em tempos de paz, empregada apenas como exercício; e que, havendo hostilidades, seja usada para atender à necessidade, pela sua glória, ficando os poderes públicos dela incumbidos como exclusividade, como em Roma. O cidadão que a usa para qualquer outro fim não age retamente; e qualquer Estado que adote outro sistema não estará bem organizado. (2007, p. 110)

Entre os elementos centrais do pensamento estratégico de Maquiavel estão

[...] non è stata mostrarvi appunto come l'antica milizia era fatta, ma comme in questi tempi si potesse ordinare una milizia che avesse più virtù che quella che si usa. (1971, p. 180) (tradução nossa).

4 Maquiavel, discorrendo sobre os grandes generais da história, diz: "Mas nenhum o teria conseguido, por maior que fosse seu valor, em um país estrangeiro, contando só com homens corrompidos, sem o hábito da obediência honesta. Não basta, portanto, na Itália, saber comandar um exército; é necessário, em primeiro lugar, saber criá-lo e depois saber conduzi-lo. Para isso, são precisos príncipes que disponham de Estados de extensão suficiente e súditos numerosos". (2007, p. 131)

5 O professor José Nivaldo Junior, em um paratexto da edição de 2007 de A Arte da Guerra, assim descreve a situação da Itália naquele período: "Nos últimos anos do século $\mathrm{XV}$, um verdadeiro terremoto político assolou a península, trazendo desordem e instabilidade. Os condottieri, mercenários contratados pelas famílias burguesas para constituir seus 'braços armados' nas disputas políticas locais e entre Estados, rebelavam-se contra seus senhores, chegando em alguns locais a controlar o poder. As disputas internas nas cidades chegam ao auge do acirramento. As rivalidades entre os principais Estados facilitam a invasão de franceses e espanhóis, que vão deixando suas marcas em todos os lugares". (MAQUIAVEL, 2007, p. 16) 
a astúcia, o segredo e a dissuasão. Diz ele:

[...] Muda de decisão quando perceberes que o inimigo a descobriu. Convém nos aconselharmos com muitos a respeito das coisas que devemos fazer; depois, devemos confiar a poucos aquilo que queremos fazer. [...] Cuidemos que nossos inimigos não saibam como queremos dispor nosso exército para a batalha [...]. (p. 128)

Porém, igualmente a Sun Tzu, dava importância capital ao conhecimento e a organização.

Em uma ordem de batalha é melhor prover reforços suficientes atrás da primeira linha do que uma frente mais ampla, com soldados dispersos. Dificilmente será vencido quem souber avaliar suas forças e as do inimigo. Mais vale a coragem dos soldados do que a multidão; e algumas vezes mais vale a situação do que o valor. [...] Quem persegue em desordem o inimigo, depois de vencê-lo, quer passar de vitorioso a derrotado. Quem não prepara os alimentos necessários para subsistir é vencido sem o emprego de armas. Os bons comandantes nunca se empenham em uma batalha se a necessidade não os impele, ou a oportunidade não os chama. (p. 128)

Como se percebe na citação acima, conceitos como força, fraqueza, ameaças e oportunidades estão, também, presentes na obra do florentino, que dista cerca de dois mil anos do texto do general chinês.

Outros trechos fundamentais do pensamento político-estratégico de Maquiavel e que constam de sua obra A Arte da Guerra (2007) são:

Quem pretende fazer alguma coisa deve primeiramente preparar-se de modo que, surgindo a ocasião, tenha condições de satisfazer suas intenções. (p. 107)

[...] os meus romanos - enquanto agiram com sabedoria e retidão - nunca permitiram que os cidadãos adotassem a profissão militar [...]. Para evitar o prejuízo que a dedicação perene à guerra poderia causar-lhes, variavam os homens, a serviço do exército, de modo que a cada quinze anos suas legiões eram renovadas. (p. 111)

O comandante de um exército que se prepara para a luta não pode fazer pior do que dispô-lo em uma única linha, de modo que a sorte da batalha seja decidida no primeiro assalto. Só fará isso quem tiver perdido o antigo conhecimento da disposição das forças em linha sucessivas, uma à frente da outra, que permite o recuo ordenado de cada uma. Sem tal dispositivo, não é possível socorrer os que estão na frente de combate, defendê-los ou substituí-los [...]. (p. 114) 
O que favorece o inimigo me prejudica; o que me favorece prejudica o inimigo. (p. 127)

Quem na guerra observar com maior vigilância as intenções do inimigo e mais exercitar seu exército, correrá menos perigos, e terá maior probabilidade de vitória. (p. 127)

Não devemos jamais conduzir os soldados à batalha se antes não nos certificamos de que seu ânimo é disciplinado, e isento de medo. Não se deve combater senão quando se vê que esperam a vitória. (p. 127)

É melhor vencer o inimigo com a fome do que com o ferro, pois na vitória obtida com este vale muito mais a sorte do que o valor. (p. 127)

Nenhum método é melhor do que aquele que o inimigo não percebe até o adotarmos. Na guerra, reconhecer a oportunidade e aproveitá-la vale mais do que qualquer outra coisa. (p. 127)

A natureza não faz muitos homens bravos; a aplicação e o exercício, sim. $\mathrm{Na}$ guerra, a disciplina pode mais que o ímpeto. (p. 127)

Os acidentes repentinos são resolvidos com dificuldade; os que foram previstos, facilmente. (p. 129)

[...] nunca ninguém foi grande na sua profissão sem criatividade. (p. 130)

[...] quando os homens desejam fazer alguma coisa, convém que primeiramente se preparem, para depois praticá-la, na ocasião oportuna. (p. 130)

[...] César, Alexandre e todos os grandes homens e príncipes ilustres eram os primeiros entre os combatentes; andavam a pé, armados [...]. (p. 133)

Essas citações permitem parceber as semelhanças entre Maquiavel e Sun Tzu no uso dos conceitos basilares do planejamento estratégico. Todavia, a diferença de contextos fez com que o florentino destacasse a importância da arte da guerra ser afrontada como uma tarefa de Estado, por conseguinte, uma tarefa pública e estratégica indelegável, que não deve ser tercerizada. Ele alerta para o perigo de se passar a condução do plano para pessoas que não estejam 
moralmente comprometidas com os objetivos do Governo (ou da organização), por isso, questões como liderança, organização, disciplina e moral da tropa são centrais em suas preocupações.

\section{O PENSAMENTO ESTRATÉGICO EM CARL VON CLAUSEWITZ}

Ele foi um general prussiano e é reconhecido como um grande estrategista e teórico da guerra. É autor do tratado Da Guerra (do alemão Vom Kriege), publicado em 1832. Um de suas feitos mais conhecidos se deu na batalha de Wavre, em 1815, quando a frente do comando do terceiro corpo do exército prussiano atraiu as forças francesas do general Grouchy, permitindo que o grosso das tropas prussianas se juntasse aos ingleses em Waterloo e impedindo que as tropas francesas reforçassem Napoleão. $O$ alcance de sua visão estratégica levou-o a se opor a uma nova guerra de vingança contra a França, pois, entendia que o enfraquecimento excessivo deste país poderia desestabilizar o equilíbrio de poder na Europa.

Sua definição de que "A guerra é meramente a continuação da política por outros meios" (2010, p.91) é sua frase mais conhecida e difundida. Na verdade este proferimento é o título do subcapítulo 24, do capítulo I, quando no texto o general diz que "O propósito político é a meta, a guerra é o meio de atingi-lo, e o meio nunca deve ser considerado isoladamente do seu propósito" (2010, p. 91). Sua visão sobre o uso da guerra pode ser avaliada por outra frase escrita no início do segundo capítulo da referida obra, na qual diz:

Se considerarmos por enquanto o puro conceito de guerra, teremos que dizer que o propósito político da guerra não possui qualquer ligação com a guerra propriamente dita, pois se a guerra é um ato de violência destinado a obrigar o inimigo a fazer a nossa vontade, o seu propósito teria que ser sempre e somente derrotar o inimigo e desarmá-lo. (2010, p. 94)

Igualmente a Sun Tzu e Maquiavel, Clausewitz trabalha todos os conceitos basilares do pensamento estratégico, passando pelo uso da força, a exploração das fraquezas do adversário, a atenção as oportunidades e a como evitar as ameaças. Dentre os três coube a ele a mais desenvolvida sistematização conceitual da diferença entre tática e estratégia aplicada ao mundo militar. Diz o prussiano: "[...] a tática ensina o emprego das forças armadas no engajamento. A estratégia, a utilização dos engajamentos para atingir o propósito da guerra” 
(2010, p. 138). Em outras palavras, a tática ensina o emprego das forças nas batalhas e a estratégia a utilização das batalhas para atingir o objetivo da guerra, ou ainda, a arte de ligar as batalhas umas com as outras. Deste modo o

[...] estrategista deve definir, portanto, uma meta para todo o aspecto operativo da guerra, que deverá estar de acordo com o seu propósito. Em outras palavras, ele esboçará o plano de guerra, e o propósito determinará a série de ações pretendidas para atingi-lo [...]. (2010, p. 199)

Assim como Maquiavel, que defendia que o comandante dos exércitos devia estar na frente de batalha, como fizeram Alexandre e Júlio César na antiguidade, Clausewitz, partindo do pressuposto de que a maioria das questões relativas ao planejamento da guerra se baseiam em pressuposições que podem não estar corretas e que as ordens mais detalhadas não podem ser estabelecidas antecipadamente, diz que "[...] o estrategista precisa estar presente na campanha. [...] Em resumo, o estrategista deve manter o controle o tempo todo" (2010, p. 199). Para ele, teoria estratégica e planejamento operacional são inseparáveis, pois, as condições da luta podem pedir a intervenção do estrategista a qualquer momento para fazer as mudanças exigidas pelo desenvolvimento da guerra. O processamento estratégico é um trabalho contínuo.

Algumas outras citações importantes de Clausewitz, em Da Guerra (2010), que compõem o seu pensamento estratégico são:

Qualquer situação determinada exige que sejam calculadas as probabilidades à luz das circunstâncias, e o tempo disponível para estes cálculos dependerá do ritmo em que estão se realizando as operações. (p. 88)

A arte da guerra trata de forças vivas e morais. Consequentemente, não pode chegar ao absoluto, nem à certeza. Deve deixar sempre uma margem para a incerteza, nas maiores e nas menores coisas. (p. 89)

As circunstâncias variam tão intensamente na guerra, e são tão inexplicáveis, que uma vasta série de fatores tem que ser avaliada - na maioria das vezes somente com base nas probabilidades. [...] Bonaparte dizia [...] que as inúmeras decisões enfrentadas pelo Comandante-em-chefe se pareciam com problemas matemáticos, dignos dos dons de um Newton ou de um Euler. (p. 123)

[...] frequentemente a ação baseia-se numa pura conjectura, ou ocorre em 
completa ignorância, seja porque o inimigo nos impede de conhecer todas as circunstâncias que podem afetar os nossos planos, ou porque não há tempo suficiente. Mesmo se conhecêssemos todas as circunstâncias, as suas implicações e a sua complexidade não permitiriam que tomássemos as medidas necessárias para lidar com elas. Nossas medidas devem ser, portanto, sempre determinadas por um número limitado de possibilidades. (p. 169)

A estratégia determina o momento e o lugar em que será travado o engajamento e as forças que dele participarão, e através desta tríplice atividade exerce uma considerável influência sobre o seu resultado. Uma vez travado um combate tático e estando assegurado o resultado, - seja a vitória ou a derrota - a estratégia o usará para servir ao propósito da guerra. (p. 220)

Os dois fatores que criam a surpresa são o sigilo e a velocidade. (p. 225)

[...] a inteligência faz malabarismos com as ideias e com as crenças, a dissimulação faz o mesmo com as ações. (p. 230)

Portanto, a regra que tentamos estabelecer é a seguinte: todas as forças destinadas e disponíveis para um propósito estratégico devem ser empregadas simultaneamente. (p. 238)

Quanto maior for o vulto dos preparativos, menor será a probabilidade de ser obtida a surpresa. (p. 239)

Uma reserva possui dois propósitos distintos. Um é prolongar e reavivar o combate. O outro é opor-se a ameaças não previstas. [...] Assim, é uma condição essencial da liderança estratégica que devam ser mantidas forças em reserva, de acordo com o grau de incerteza estratégica. (p. 239)

O grau da nossa própria fraqueza e inadequabilidade revela-se de uma maneira demasiadamente evidente na quantidade de troféus tomados pelo inimigo [...]. (p. 266)

[...] a defesa sem um propósito ativo é uma incoerência, tanto na estratégia como na tática, e, consequentemente, devemos repetir que, dentro dos limites das suas forças, um defensor deve sempre procurar passar para o ataque logo que tiver obtido os benefícios da defesa. (p. 711) 
Além da sistematização conceitual da diferença entre tática e estratégia, até hoje usada pelos estudiosos e consultores em planejamento estratégico, Clausewitz aprofundou a reflexão em torno de outros conceitos, tais como: situação; cálculo de probabilidades à luz das circunstâncias; encadeamento das ações no tempo; a importância de se trabalhar com a incerteza, etc. Outra característica importante do seu processamento estratégico é a visão do todo, da macropolítica à geopolítica continental.

\section{O PENSAMENTO ESTRATÉGICO EM CARLOS MATUS ROMO}

Este economista chileno formou-se em 1955 na Universidade do Chile e durante o governo socialista de Salvador Allende (1965-1970), entre outras funções, ocupou a pasta de ministro da economia.

Allende foi derrubado por um golpe de estado que resultou no assassinato do presidente e na prisão de Matus. No cárcere e, depois, no exílio, a partir de 1975, o ex-ministro intensificou sua crítica ao planejamento normativo e começou a formular as bases metodológicas do Planejamento Estratégico Situacional, o PES. O ponto de partida de sua reflexão foi dar resposta à pergunta: Por que um governo com tanta popularidade e com tão boas intenções caiu de forma tão fragorosa diante de um golpe militar?

Ainda em Santiago do Chile, participou do Instituto Latino-americano de Planejamento Econômico e Social - ILPES, organismo vinculado a Comissão Economica para América Latina - CEPAL e, em Caracas, no ano de 1988, organizou a Fundação Altadir (de alta direção), com o objetivo de desenvolver e disseminar a metodologia do PES e suas técnicas de governo e de direção.

Atualmente, Matus é reconhecido como um grande estudioso sobre planejamento estratégico, governabilidade, estratégias e capacidade de governo. Ministrou cursos no Brasil na década de 1990 e cooperou diretamente com a Fundação Oswaldo Cruz - Fiocruz e o Departamento Intersindical de Estatística e Estudos Socioeconômicos - Dieese, além da Central Única dos Trabalhadores - CUT, diversos governos municipais, entre outras instituições que buscavam aprimorar sua capacidade de gestão. De tal modo, o PES disseminou-se em nosso país e foi adaptado amplamente no setor público. Influenciou gestores, estudiosos, consultores em planejamento estratégico e pesquisadores no mundo todo. Centenas de artigos, dissertações e teses acadêmicas foram escritos refletindo sobre o pensamento estratégico 
matusiano.

Matus utilizou a acumulação histórico-conceitual de Sun Tzu, Maquiavel e Clausewitz para formular seu conceito de planejamento estratégico. Para ele,

O planejamento é a ferramenta para pensar e criar o futuro porque contribui com um modo de ver que ultrapassa as curvas do caminho e chega à fronteira da terra virgem ainda não palmilhada e conquistada pelo homem. Essa visão ampla serve como suporte das decisões de cada dia: os pés no presente e o olhar no futuro. (HUERTAS, 1996, p. 12)

Por conseguinte, o planejamento é um processo permanente pelo qual se desencadeia um conjunto de ações articuladas entre si e coordenadas no tempo para que se alcancem os objetivos estabelecidos. A vida real é rodeada de incertezas e o planejamento se desenvolve nesse meio resistente, onde o futuro é nebuloso e impredizível. No jogo social e político contemporâneo interagem diversos atores que concorrem pelos mesmos objetivos criando uma situação de disputa total ou parcial, por isso, o planejamento não é tarefa de planejadores e dos seus escritórios de consultoria, mas sim de quem executa, ou seja, de quem joga o jogo social e, portanto, está submergido na ação.

O poder é um recurso escasso para os atores e compartilhado entre estes, o que significa que cada ator governa partes do tabuleiro onde se desenvolve o jogo social, por menor que possa ser esse poder. A capacidade e a qualidade do plano de cada ator garantirão certa posição no jogo. Esta apreciação levou Matus a redefinir os conceitos de estratégia e tática do ponto de vista da realidade político-social do final do século XX e de seu uso no PES, para o qual “[...] tática é o uso dos recursos escassos na produção de uma mudança situacional, e estratégia é o uso da mudança situacional para alcançar a situação objetivo" (HUERTAS, 1996, p. 72). Como é bem noto, a definição do chileno é um amoldamento para o mundo moderno do conceito de Clausewitz.

Matus, ainda define planejamento como o "[...] cálculo que precede e preside a ação" (1989, p. 24). É um cálculo situacional e sistemático que articula diferentes horizontes de tempo e envolve todas as dimensões da realidade. Planejamento é cálculo! Um cálculo situacional que analisa o movimento real da sociedade e a dinâmica de produção e reprodução social, onde o sujeito que planeja faz parte do objeto planejado. Ao interior deste estão, também, os demais sujeitos que, igualmente, planejam. Desse modo, atores sociais e objeto planejado não se distinguem e nenhum ator tem assegurado o resultado do jogo, pois a capacidade de controlar a realidade planejada é limitada pela ação do outro. É um jogo de interdependências, onde o movimento de um ator é 
condicionado pelo movimento dos outros e vice-versa. O controle das variáveis do jogo determinará os diferentes graus de governabilidade do sistema para cada ator social.

A capacidade de planejamento de cada ator é diferenciada e cada um explica a realidade a partir do lugar que ocupa no contexto do jogo. Trata-se, portanto, de uma explicação particular e condicionada pelas crenças e valores de cada ator. Nas palavras de Matus,

A explicação é uma leitura dos dados e informações que expressam a realidade. Cada ator retira da realidade uma interpretação dos fatos, conforme a lente com que os observa. Toda explicação é declarada por alguém, e esse alguém é um ser humano que tem seus valores, suas ideologias e seus interesses. Sua leitura esta carregada de subjetividade e está animada por um propósito. (HUERTAS, 1996, p. 30)

Portanto, não há uma única explicação que possa ser considerada verdadeira, coexistem ao interior da sociedade várias explicações que são por natureza situacionais.

A execução de um plano se dá em meio a sistemas sociais complexos onde a maioria dos problemas não são estruturados e sim quase estruturados ${ }^{6}$. A seleção e análise dos problemas requerem o reconhecimento das variáveis cujo desenvolvimento impactarão na solução destes.

Num contexto assim complexo o planejamento não deve ser um ato mecânico que se confunda com o desenho normativo do planejamento tradicional, o qual considera o deve ser como algo inexorável. No PES, "o desenho normativo embasa-se no pode ser que se realizará (ou não) de acordo com a capacidade do ator que planeja de realizar e sistematizar um cálculo político e situacional para atuar na conjuntura” (DAROS, 2014, p. 30).

O futuro no jogo social está repleto de incertezas e a acumulação (ou desacumulação) de forças será tanto maior (ou menor) de acordo com a capacidade de se fazer o cálculo que deve preceder e presidir a ação. Este cálculo é interativo e feito a partir da perspectiva de quem explica, ou seja, da sua visão de mundo, das suas relevâncias e de como o ator se situa no contexto. Esta explicação é situacional, onde a categoria situação é compreendida como a

6 Costa diz que um problema é estruturado quando: é possível enumerar todas as variáveis que o compõem; é possível precisar todas as relações entre as variáveis e é possível reconhecer sua solução como tal por todos os jogadores. Já um problema é quase estruturado quando: podem-se enumerar apenas algumas variáveis que o compõem; podem-se precisar apenas algumas das relações entre as variáveis e podem-se entender suas soluções como, necessariamente situacionais, isto é, aceitáveis para um ator e vistas com restrições por outros (2013, p. 210). 
realidade explicada por um ator que vive nela e quer modificá-la. $\mathrm{O}$ ator explica uma determinada realidade - a situação inicial $(\mathrm{Si})$ - com o propósito de transformá-la e de alcançar uma nova realidade - a situação objetivo (So). Para Matus, "Ganho liberdade a medida que penso e enumero possibilidades futuras, porque me liberto da cegueira ou da prisão de não saber que posso escolher ou, pelo menos, tentar escolher" (HUERTAS, 1996, p. 18). Portanto, para um bom estudo de cenários deve-se ter presente que entre a situação inicial e a situação objetivo há uma série de variáveis $(\infty)$ que poderão produzir fatos que irão incidir sobre o plano, impactando-o de forma negativa ou positiva. E que os demais atores sociais disputam o controle dessas variáveis e, ainda, que estes podem ser aliados ou adversários do plano ou, inicialmente, ter posição neutra. No esquema abaixo estes princípios estão sintetizados:

\section{$\mathrm{O}$ ator formula e escolhe um plano, mas não as circunstâncias nas quais vai executá-lo.}

(eu e o(s) outro(s) em perspectivas diferenciadas).

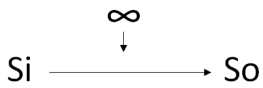

Quanto mais controle um ator social tem sobre as variáveis, melhores serão as suas condições para alcançar o objetivo do plano.

A eficácia dos movimentos de um ator depende da movimentação dos demais. A incerteza, característica predominante em sistemas sociais, requer cálculos condizentes com esta situação, o que significa que estes sejam relativizados e embasados em apostas sobre as quais não se pode haver certeza da ocorrência por serem difusas. O cálculo, ancorado em previsões, deve ser diverso e permanente para que o ator que planeja possa reagir com rapidez diante da possibilidade de mudanças e de surpresas. Para enfrentar a incerteza é necessário consciência da sua existência e fuga da comodidade do planejamento determinístico, que congela a explicação situacional dentro de um diagnóstico.

Para Matus, "A realidade gera problemas, ameaças e oportunidades" (HUERTAS, 1996, p. 35) e adverte que "Governar exige encarar os problemas. Evitá-los ou postergá-los somente aumenta o custo futuro de lidar com eles" (MATUS, 1996, p. 270). Portanto, um problema é algo que contraria a visão de mundo e as aspirações do projeto do ator e que, portanto, está dentro da sua 
possibilidade de atuação, ou seja, dentro do seu espaço de governabilidade. Por seu intermédio o ator media a realidade e o seu valor será dado pela carga particular de ideologias, valores e conhecimentos do ator que participa no jogo social.

Algumas outras citações basilares do pensamento estratégico de Matus são:

Quanto mais variáveis decisivas controla um ator, maior é sua liberdade de ação e maior é para ele a governabilidade do sistema. Quanto menos variáveis de peso controla, menor será sua liberdade de ação. (1989, p. 35)

A governabilidade de um sistema é relativa a um ator determinado, às demandas ou exigências que o projeto de governo coloca para este ator e à capacidade de governo do ator pertinente. (1989, p. 35)

[...] um sistema não é igualmente governável ou ingovernável para os distintos atores sociais, pois cada um deles controla uma proporção distinta de variáveis do sistema. (1989, p. 35)

O domínio de técnicas potentes de planejamento é uma das variáveis mais importantes para a determinação da capacidade de uma equipe de governo [...]. A capacidade de governo se expressa em capacidade de direção, de gerência e de administração e controle. (1989, p. 35)

Em síntese, Matus em sua formulação estratégica trabalha com todos os conceitos que perpassaram o pensamento dos três estrategistas que o antecederam, contudo, sua preocupação central é o uso deles no planejamento governamental, a serviço de políticas que sirvam à melhoria da qualidade de vida dos cidadãos. Assim, a guerra é uma espécie de metáfora que ajuda a refletir sobre o uso dos conceitos do planejamento estratégico no processamento de políticas na esfera pública.

\section{CONSIDERAÇÕES FINAIS}

Como já dito, o tratado de Sun Tzu sobre a guerra teve sua primeira tradução para o ocidente publicada em Paris, em 1772, feita por Amiot. O General Samuel B. Griffith, no prefácio de sua tradução para o inglês de A Arte da Guerra, diz que "Publicações da época trouxeram resenhas favoráveis sobre o livro e o trabalho de Amiot teve ampla aceitação. [...] É possível que tenha sido lido por Napoleão [...]" (Sun Tzu, 1996, p. 8). Portanto, apesar das semelhanças 
entre o seu texto e o de Sun Tzu, é improvável que Maquiavel tenha tido contato com os escritos do general chinês quando ele escreveu sua homônima obra. Os dois livros trabalham meios estratégicos importantes como a informação, o segredo, a dissuasão, o conflito, as manobras, o engodo, o uso das forças, a exploração das fraquezas, etc. A obra de Sun Tzu é mais pragmática, com destaque para sua filosofia que propõe vencer sem desembainhar a espada, e no caso da inevitabilidade da guerra que o seu tempo de duração seja o mais breve possível, economizando recursos e vidas. Ele, ainda destaca que é melhor conquistar uma nação sem destruí-la. A Arte da Guerra de Maquiavel narra em forma de diálogo os seus pensamentos sobre estratégia militar, mas, tendo como pano de fundo a situação política da Itália no período. O florentino, ao constatar que as cidades-estado italianas eram carentes de exércitos e de lideres, demonstra como deve ser formado um exército e como se dá a relação entre os assuntos civis e militares na formação de uma grande estratégia. Segundo ele, para formular uma boa estratégia o exército moderno deve ser organizado, composto por soldados dedicados, ordenado por divisões de comandos bem estruturadas e coeso. Para uma melhor compreensão da dimensão e complexidade dos escritos militares de Maquiavel, além da análise do contexto da época, é importante a leitura de outras obras suas, especialmente O Príncipe e os escritos políticos.

Clausewitz conhecia Maquiavel e, possivelmente, Sun Tzu, uma vez que este era conhecido por seu antagonista, o general Napoleão. Os escritos deles provavelmente ajudaram-no na formulação da sua concepção trinitária da guerra, que consiste na relação entre a violência, o jogo das probabilidades e do acaso, e a finalidade racional. A guerra enquanto violência organizada por motivações políticas requer tática (combates, batalhas) e estratégia (clareza do objetivo da guerra). A respeito da influência do secretario florentino sobre o general prussiano, Rodrigo Passos (2014) diz:

É fato que temas maquiavelianos parecem ecoar em Clausewitz: a adequação entre fins e meios, a atração pelos temas e realidades envoltas pelo poder, a definição de guerra no início de Da guerra como fenômeno externo a ética e distanciado de outros constrangimentos relacionados à bondade (tal como na política), a visão do mundo político como algo permanentemente em fluxo, sem término, a centralidade da formulação maquiaveliana para os homens de ação política [...]. (p. 152)

Já Matus, conhecia os três e foi um estudioso do diplomata florentino e do general prussiano. No livro Estratégias Políticas ele faz uma importante reflexão 
sobre o conceito de estratégia de Maquiavel e, também, estuda Clausewitz. É notória a influência deste na formulação matusiana dos conceitos de estratégia e tática. Para o economista chileno importa a dinâmica do jogo social e seus atores e, de tal modo, estes conceitos ganharam uma metodologia para aplicação na atualidade da ação governamental e social.

Enfim, estes quatro teóricos do pensamento estratégico consubstanciaram com suas produções intelectuais as bases fundamentais para a elaboração dos conceitos contemporâneos de estratégia e tática que são largamente utilizados no planejamento estratégico de governos, de instituições da sociedade civil e, do mesmo modo, na esfera privada.

\section{REFERÊNCIAS}

CLAUSEWITZ, Carl Von. Da guerra. Tradução para o inglês Michael Howard e Peter Paret. Tradução do inglês para o português Luiz Carlos Nascimento e Silva do Valle. São Paulo: Editora WMF Martins Fontes, 2010.

DAROS, Romeu Porto. $\mathbf{O}$ desafio do agir estrategicamente em governos locais: a experiência do planejamento estratégico na prefeitura de Brusque/SC. Trabalho de conclusão do curso de Especialização em Gestão e Políticas Públicas, Fundação Escola de Sociologia e Política de São Paulo, 2014. $79 \mathrm{p}$.

HUERTAS, Franco. O método PES: entrevista com Matus. Trad. Giselda B. Sauver. São Paulo: FUNDAP, 1996.

MACHIAVELLI, Niccolò. Dell'arte della guerra. Firenze: Einaudi, 1971.

A arte da guerra. Tradução de Eugênio Vinci de Moraes. Porto Alegre: L\&PM, 2007.

MATUS, Carlos. Adeus, Senhor Presidente: governantes governados. Trad. Francisco A. C. da Cunha Filho. Recife: Litteris Editora Ltda, 1989. . Estratégias Políticas: Chimpanzé, Maquiavel e Ghandi. São Paulo: Edições FUNDAP, 1996.

MINTZBERG, Henry; QUIN, James B. O processo da estratégia. Porto Alegre: Bookman, 2001.

OLIVEIRA, D.P.R. Estratégia empresarial \& vantagem competitiva: como 
estabelecer, implementar e avaliar. 6 Ed. São Paulo: Atlas, 2009.

PASSOS, Rodrigo Duarte Fernandes dos. Maquiavel e Clausewitz: Da arte da guerra à política por outros meios. In: Reflexões sobre Maquiavel. Rafael Salatini \& Marcos Del Roio (org.). - Marília: Oficina Universitária; São Paulo: Cultura Acadêmica, 2014, p. 145-156.

TZU, Sun. A arte da guerra. Tradução do chinês para o inglês por Samuel B. Griffith e para o português por Gilson César Cardoso de Souza e Klauss Brandini Gerhardt. - Rio de Janeiro: Paz e Terra, 1996.

A arte da guerra. Traduzido do chinês para o francês pelo padre Amiot em 1772 e traduzido do francês por Sueli Barros Cassal. Porto Alegre: L\&PM, 2006.

\section{EL PENSAMIENTO ESTRATÉGICO EN SUN TZU, MAQUIAVELO, CLAUSEWITZ Y CARLOS MATUS}

Resumen: El presente artículo tiene como objetivo hacer un paseo panorámico por el pensamiento estratégico de cuatro exponentes de este campo en la historia de la humanidad: dos generales y teóricos de la estrategia militar (Sun Tzu y Carl Von Clausewitz) y dos políticos y teóricos de la estrategia gubernamental (Nicolás Maquiavelo y Carlos Matus). La producción intelectual de ellos fue fundamental para el desarrollo de los conceptos contemporáneos de la estrategia y táctica que son ampliamente utilizados en la planificación estratégica de los gobiernos y también en el sector privado.

Palabras clave: Estrategia. Táctica. Planificación Estratégica. Política. Guerra. 


\title{
STRATEGIC THINKING IN SUN TZU, MACHIAVELLI, CLAUSEWITZ AND CARLOS MATUS
}

\begin{abstract}
This article presents an overview of the strategic thinking of four exponents in the history of humanity: Two theorist generals of military strategic (Sun Tzu and Carl Von Clausewitz) and two theorist politicians of government strategy (Nicolau Machiavelli and Carlos Matus). The intellectual production of them was elementary in the preparation of contemporaneous concepts of strategy and tactic that are widely used in the strategic of governments planning and also within the private sector.
\end{abstract}

Key-words: Strategy. Tactic. Strategic planning. Politics. War. 